\title{
AUTO-PERCEPÇÃO DE ALUNA DE ENFERMAGEM AO DESENVOLVER RELAÇÃO DE AJUDA A FAMILIARES DE CRIANÇA EM FASE TERMINAL*
}

Marisa Lorençon**

LORENÇON, M. Auto-percepção de aluna de enfermagem ao desenvolver relação de ajuda a familiares de criança em fase terminal. Rev.latino-am.enfermagem, Ribeirão Preto, v. 6, n. 4, p. 57-65, outubro 1998.

O presente estudo visa relatar e analisar o processo de relacionamento terapêutico entre aluna de enfermagem e mãe de criança internada em UTI pediátrica, em fase terminal. As interações desenvolvidas neste processo foram gravadas e analisadas no enfoque do Relacionamento Terapêutico. Utilizando técnicas de comunicação terapêutica e medidas terapêuticas de enfermagem, a aluna envolveu-se empaticamente com a mãe da criança e com os demais familiares, propondo-se a ajudá-los a superar suas dificuldades diante da criança em fase terminal. Neste estudo a aluna analisa a sua própria ansiedade diante da situação e as dificuldades que teve devido aos seus conflitos diante da terminalidade do seu paciente.

UNITERMOS: unidades de terapia intensiva pediátrica, paciente terminal, relacionamento terapêutico

\section{INTRODUÇÃO}

A enfermeira, ao cuidar de criança em fase terminal, depara-se com a angústia e a dor dos familiares, assim como com a sua própria dificuldade em lidar com esta situação. Particularmente por tratar-se de criança, é freqüente o envolvimento emocional e a dor pela perda do paciente.

Devido à natureza da sua atividade, a enfermeira está ativamente envolvida na situação e com freqüência age intuitivamente no cuidado da criança e no apoio aos seus familiares (GROOT-BOLLÜJT \& MOURIK,1993). É importante combinar a sensibilidade ao conhecimento teórico, com a finalidade de oferecer uma assistência de enfermagem planejada e estruturada, visando a orientação aos familiares a respeito do que ocorre e estimulando a expressão do seus sentimentos.

Segundo KÜBLER-ROSS (1987), os familiares de crianças gravemente enfermas experimentam sentimentos diante da ameaça da perda de uma forma semelhante a todos os seres humanos defrontando com situações trágicas. Inicialmente, o choque leva à negação, que se caracteriza pela recusa em aceitar a realidade. Seguem-se sentimentos de raiva contra a equipe, contra eles próprios, contra Deus. Tentam a seguir barganhar, fazendo concessões, tentando adiar o inevitável. Conscientizando-se da realidade dos fatos, a raiva dá lugar ao sentimento de tristeza e desânimo, como se já antecipassem a perda. Este processo todo poderá levar à aceitação, que promove a redução da angústia e a possibilidade de expectativa do que ocorrerá, com uma relativa tranqüilidade. Neste caminhar dos familiares ao lado da criança em fase terminal, a equipe que a assiste deve centrar-se na intervenção e na informação clara e verdadeira sobre o que ocorre, procurando um equilíbrio cuidadoso entre manter a família na realidade, respeitar e estimular para que mantenham a esperança (ZAVASCHI, 1993).

São poucos trabalhos na literatura que tratam especificamente do relacionamento que se estabelece entre enfermeira e os familiares de criança em fase terminal. Dentre eles, podemos citar alguns que se preocupam com os aspectos que estudamos.

$\mathrm{Na}$ literatura internacional, JEFIDOFF \& GASNER (1993) descrevem uma experiência de orientação aos familiares de crianças em fase terminal e concluem que o papel mais importante desempenhado pelas enfermeiras foi o apoio à criança e a família, estimulando-as a expressar os seus sentimentos.

COX (1994), em trabalho sobre o cuidado da criança com injúrias traumáticas, salienta o papel da enfermeira ao oferecer apoio, conforto e informações aos membros da família.

Para GROOT-BOLLÜJT \& MOURIK (1993), a enfermeira faz parte do sistema de suporte aos familiares, ao orientar e informar. Para tanto, na

\footnotetext{
* Trabalho desenvolvido na Disciplina de Relacionamento Enfermeira-Paciente, orientado pelas professoras doutora Maria Lúcia A.Sadala, e doutora Ione Corrêa do Curso de Graduação em Enfermagem da F.M. de Botucatu, UNESP

** Enfermeira (aluna do Curso de Enfermagem F.M. de Botucatu no período do desenvolvimento do trabalho)
} 
perspectiva dos autores, ela deve observar como os pais enfrentam a situação através da comunicação verbal e não verbal e compreender as fases do processo de aceitação da morte, como descrita por KÜBLER ROSS (1987), para poder entender a reação dos pais e deixar claro para eles que suas questões são levadas a sério e respondidas.

$\mathrm{Na}$ literatura brasileira, alguns, dentre os autores consultados descrevem as reações dos profissionais e familiares diante da terminalidade do paciente pediátrico. HORTA (1982) descreve os sentimentos de tristeza e a culpa da criança ao não se perceber mais como um ser com futuro, impossibilitada de realizar seus sonhos, expectativas e desejos, e causando ainda uma profunda decepção aos pais, frustrando-os também nas suas expectativas.

BOEMER (1984) ressalta que a situação de terminalidade é um desafio para a equipe de saúde, principalmente para a enfermagem que, no exercício da profissão, convive nos hospitais com situações de vida e morte em seu cotidiano.

BOEMER \& VALLE (1988), em trabalho a respeito da assistência à criança portadora de câncer, descrevem a percepção que as enfermeiras têm de si mesmas nesse cuidar: seus sentimentos de angústia, dúvidas, receios, preocupações, considerando que essas profissionais precisam ser preparadas para uma visão da morte como uma das possibilidades ao cuidar da criança com câncer, a fim de que possam compartilhar da sua experiência de finitude.

VALLE (1995), analisando as reações dos pais frente à morte eminente da criança com câncer, descreve suas dificuldades para aceitar a situação, e salienta a função da equipe de saúde ao preparar os pais. Segundo a autora, há necessidade de acompanhar a criança que está morrendo de modo que esta não se perceba já morta pelos pais e pela equipe, ou seja, procurando expressar, pelo cuidado constante, que há esperança e se está investindo nela como um ser vivo.

Em estudo a respeito da reação de crianças e adolescentes diante da morte, ZAVASCHI (1993) ressalta o papel dos profissionais de saúde como o anteparo para todas as ansiedades do paciente e de sua família. Descreve como é freqüente a equipe afastar- se emocionalmente do paciente, e vivenciar sentimentos de depressão, prejuízo do raciocínio clínico, desumanização do atendimento, além de conflitos entre os membros da equipe, em resposta à angústia dos familiares.

A nossa preocupação neste estudo volta-se para o desenvolvimento de apoio aos familiares da criança em fase terminal, de forma sistemática e planejada, entendendo que apoio é a medida básica no processo de relação de ajuda que se estabelece entre a enfermeira e o paciente e familiares, podendo ser implementada de forma mais eficiente mediante a utilização das técnicas da comunicação terapêutica (STEFANELLI, 1993; SUNDEEN et al., 1985).

STEFANELLI et al. (1982) e STEFANELLI (1993) propõe a utilização de formas de comunicação planejadas e estruturadas com o objetivo de reduzir a ansiedade do paciente em relação às situações que vivencia, estimulando a sua conscientização e a sua participação na assistência. Para tal fim, são utilizados os recursos de comunicação terapêutica: estratégias de comunicação que estimulam a expressão dos pensamentos e sentimentos do paciente e medidas terapêuticas de enfermagem: oferecimento de apoio e estabelecimento de limites, que propiciem a diminuição da ansiedade e estimulem sentimento de confiança para o paciente.

SUNDEEN (1985) descreve o processo do relacionamento terapêutico como série de interações estruturadas e planejadas, com objetivo claramente estabelecido, em conjunto com o cliente, no sentido de oferecer-lhe ajuda e estimulá-lo ao auto - cuidado. Este processo é analisado pela autora numa seqüência de fases, desde o preparo do profissional para o relacionamento de ajuda, passando pelo desenvolvimento da relação e a finalização, que inclui a avaliação do trabalho desenvolvido juntamente com o cliente. Neste processo, são elementos importantes a participação ativa do cliente e a conscientização da enfermeira a respeito do seu papel, assim como dos seus sentimentos e expectativas.

Baseado no referencial citado, o presente estudo se propõe a descrever e analisar o relacionamento desenvolvido por aluna de enfermagem, junto aos familiares de uma criança internada em unidade de terapia intensiva (UTI), durante atividades de assistência de enfermagem.

\section{MÉTODO}

Trata-se de uma pesquisa qualitativa, desenvolvida na Enfermaria Pediátrica de um hospital escola. Os dados foram coletados pela aluna mediante a realização de três entrevistas não estruturadas gravadas com a mãe e o pai; uma entrevista não estruturada gravada com o irmão da criança; observação da família; consulta ao prontuário; informações dos profissionais da UTI e interações informais desenvolvidas entre a aluna e a família.

As interações foram transcritas e analisadas procurando-se analisar os significados dos sentimentos das pessoas envolvidas e do que aconteceu, segundo o referencial da comunicação terapêutica (STEFANELLI, 1993; SUNDEEN, 1985). 
DADOS DO PRONTUÁRIO DO PACIENTE

V.R.H.P., sexo masculino, 5 anos, procedente de São Paulo. Deu entrada no P.S. no dia 08/07/95 com traumatismo craniano por acidente automobilístico, inconsciente. A tomografia revelou importante edema cerebral e hematoma subdural pequeno à esquerda. Foi encaminhado à unidade de terapia intensiva pediátrica (UTI). Não responsivo a estímulos dolorosos e com eletroencefalograma (EEG) isoelétrico, recebeu a hipótese diagnóstica de "morte cerebral".

Y., irmão da criança acidentada tinha oito anos e estava internado na enfermaria de pediatria em observação médica, pois no acidente ficou inconsciente por alguns minutos e ao acordar referiu forte dor na cabeça.

\section{ANÁLISE E DISCUSSÃO DOS DADOS}

O relacionamento com o irmão da criança acidentada (Y.) e os pais desenvolveu-se durante dois dias, em seis interações.

\section{INTERAÇÃO (Fase de pré-interação)}

\section{1/07/95. Terça-feira. Local: UTI Pediátrica \\ Horário: 13:00 horas}

A aluna encontrava-se na UTI da pediatria desenvolvendo um trabalho de apoio às mães das crianças ali internadas. Deparou-se com uma criança acidentada que, segundo a enfermeira, "iria a óbito". A aluna interessou-se em oferecer apoio à mãe da criança, mas sentiu ansiedade diante da situação, percebia-se incapaz de ajudá-la. Observou a mãe, próxima da criança, falandolhe: "você é forte meu filho, acorda, volta prá mim".

Acompanhada pela docente de Pediatria, iniciou a leitura do prontuário da criança e verificou que havia suspeita de "morte encefálica". O caso era difícil. A aluna continuava indecisa sobre relacionar-se com a família da criança, quando um acidente chamou-lhe a atenção: uma visitante entrou na UTI e reagiu de modo descontrolado diante de uma criança de seis meses de idade, o que a fez pensar na importância de preparar os familiares para entrar na UTI.

Logo após, ao observar o irmão de V. (Y.), interagindo com ele, decidiu-se a prestar assistência à família. O menino falava-lhe, tocava-o e colocava bilhetes nas mãos de V.. A aluna emocionou-se, aproximou-se e interessou-se em saber o que ele escrevia para V.. O menino autorizou-a a ler os bilhetes. Dizia ao irmão que o amava e sentia a sua falta.
ANÁLISE

A aluna teve o seu interesse despertado ao observar V., pensou no sofrimento da mãe e da família. Queria ajudá-los mas, diante da falta de experiência em lidar com criança em fase terminal, sentiu-se ansiosa. Resultados semelhantes foram encontrados por BOEMER \& VALLE (1988). Entretanto, observando as reações dos familiares diante da criança em estado crítico, percebeu como é importante a orientação à família para possibilitar que ela compreenda a situação que está vivenciando, e participe efetivamente dessa assistência.

A aluna, ao se aproximar de Y., fez perguntas e, quando se emocionou excessivamente, percebeu que poderia agir de modo não terapêutico caso se envolvesse além do adequado, perdendo a objetividade no relacionamento.

\section{$2^{n}$ INTERAÇÃO (Fase inicial)}

11/07/95. Local: Enfermaria Pediátrica - quarto onde Y., irmão da criança acidentada, estava internado

Horário: 14:30 horas

A aluna e a docente apresentaram-se à mãe da criança e ao irmão. Ambos dialogavam sobre o estado de V.. A mãe fala à criança sobre a possibilidade de V. morrer. O pai entra no quarto, preparando-se para a alta de Y.

A aluna fala com a mãe e o pai de Y. e pede autorização para falar com a criança. A mãe consulta a criança e esta rapidamente diz que não queria responder perguntas, que não se lembrava de nada do acidente. A aluna garante à criança que só falariam sobre o que ela quisesse e que não perguntaria nada sobre o acidente. Houve silêncio e aluna temeu não ser aceita. Quando a criança concordou, autorizada pela mãe, dirigiram-se para o pátio da pediatria.

\section{ANÁLISE}

Nesta interação a aluna precipitou-se, ao propor a interação com a criança e segundo SUNDEEN (1985), a aluna deveria nesta fase se identificar e explicar claramente o trabalho que estava sendo desenvolvido. Isso aconteceu, devido ao receio de que a criança já fosse embora. Sentiu também receio de que a criança não a aceitasse.

\section{$3^{\mathrm{a}}$ INTERAÇÃO (Fase de desenvolvimento)}

\section{1/07/95. Local: Pátio da Enfermaria Pediátrica} Horário: 15:00 horas

Durante o trajeto, a criança autorizou que a entrevista fosse gravada e a aluna começou o diálogo 
perguntando a sua idade e sobre o que queria conversar. Ficou surpresa quando a criança começou a falar espontaneamente sobre o acidente. Disse: "sabe, eu e o meu irmão fomos jogados para fora do carro quando capotou". Então você sabe que o carro capotou e vocês foram jogados para fora? E o que mais você sabe? perguntou a aluna. Y. respondeu que foram para um hospital e depois vieram para cá.

Após ouvir isto, a aluna tentou estimular a criança a expressar os seus sentimentos em relação ao acontecido. Perguntou à criança o que ela havia sentido quando soube do estado do irmão, como ela havia ficado e o que ela sentiu naquele momento. Y. não respondeu e como ficou em silêncio, a aluna mudou de assunto.

Mais tarde Y. contou que não ficou assustado e nem sentiu medo quando entrou na UTI porque a sua mãe já tinha lhe contado como V. estava. Disse que achou o irmão gelado e sabia que ele ia subir para o céu.

A aluna perguntou o que ele achava disto e ele respondeu: "eu não quero perder o meu irmão. Eu vou sentir a falta dele, vai ser triste. Eu não vou mais ver o V.". A aluna ficou em silêncio e Y. perguntou : "será que eu não vou ver o V. nunca mais ?"

"O que você acha?" - perguntou a aluna. "Acho que se ele subir e eu quiser vê-lo, eu posso. O papai do céu me ajuda", respondeu o menino.

A aluna ficou surpresa e perguntou: "como Y.?" E o menino respondeu: "eu peço pra ele mostrar V. no sonho". Houve silêncio e a aluna achou-o triste. Resolveu mudar de assunto, pedindo para que ele falasse um pouco em japonês.

A seguir, a aluna perguntou se Y. queria falar alguma coisa e ele respondeu: "eu não quero perder o meu irmão". "Você acha que vai perdê-lo?" - perguntou a aluna. "Não, quando ele acordar nós vamos brincar", respondeu a criança.

A aluna perguntou para a criança o que ele gostaria de falar para o irmão naquela hora, e Y. apontou para o gravador: "se eu falar aí você leva para ele ouvir?" A aluna confirmou e Y. gravou a mensagem: "V., reage... reage. Estou com saudade de você. Eu quero que você volte logo". Após ouvir a mensagem, a aluna se emocionou, mas esforçou-se para se controlar.

Voltaram para a enfermaria e a aluna convidou Y. para se despedir do irmão na UTI. Ficou satisfeita com a concordância dos pais e o interesse do menino em visitar o irmão novamente.

Na UTI, a aluna observou os gestos do menino e viu sua alegria quando disse: "olhe, ali está mexendo", apontando para o tórax do irmão. A aluna achou importante, explicar a ligação do respirador mecânico com a expansão torácica perguntando, a seguir, se ele havia entendido o que estava acontecendo. Respondeu que sim. Depois de alguns minutos, retiraram-se da UTI.

\section{ANÁLISE}

Para facilitar esta interação, foi necessária a utilização de perguntas e a verbalização de aceitação e interesse pela criança. A aluna permitiu que ela escolhesse $o$ assunto e considerou que isto foi fundamental para $o$ desenvolvimento do relacionamento, pois a própria criança quis falar sobre o acidente.

Quando a aluna perguntou sobre os sentimentos da criança, percebeu que houve ausência de linguagem comum após o silêncio e a falta de respostas de Y.. A aluna refletiu mais tarde que poderia ter pedido para que a criança desenhasse ou escrevesse, o que facilitaria a sua expressão diante da condição clínica do irmão (da perda). Também não pediu para a criança validar*** o que lhe foi descrito na UTI quanto à expansão torácica e induziu a resposta. Portanto, agiu de modo não terapêutico.

Mas, no geral, considerou que teve a aceitação e confiança da criança, estimulou-a a expressar o que sentia em relação à condição em que o irmão se encontrava, ajudando-a a compreender a realidade dos fatos, os riscos que o irmão ainda corria, procurando manter a sua esperança na recuperação do irmão.

\section{$4^{\mathrm{a}}$ INTERAÇÃO}

\section{1/07/95. Local: Corredor da Enfermaria Pediátrica. Ao lado da UTI \\ Horário: 16:00 horas \\ A aluna apresentou-se aos pais, dizendo ser aluna} do Curso de Graduação em Enfermagem. Explicou que estava ali para realizar um trabalho de acompanhamento às mães de crianças internadas na UTI. A mãe quis saber detalhes e a aluna explicou-lhe que pretendia orientar a mãe e a família quanto a patologia e a assistência de enfermagem à criança; esclarecer aos pais como encontrarão o filho lá dentro, e promover um maior contato físico entre eles. Disse ainda que sabia ser difícil para uma mãe ou para um pai entrar na UTI e ver o filho com sondas e tubos, ligado a aparelhos. A aluna foi interrompida pelo pai que concordou dizendo que se sentiam desorientados e que não conheciam ninguém na cidade. Achou bom ter alguém para orientá-los.

A aluna disse-lhes que sua intenção era estar sempre que possível perto deles e esclarecê-los quando

\footnotetext{
*** Validar: termo específico do referencial de Comunicação Terapêutica (STEFANELLI, 1993), significando confirmar explicitamente a compreensão do conteúdo da mensagem
} 
necessário. Depois, ofereceu o apoio dizendo: "eu sei que este momento é muito difícil para vocês, mas se vocês não querem conversar sobre este assunto, tudo bem. Eu não quero que vocês se sintam obrigados a falar. Eu estou aqui à disposição de vocês". Os pais concordaram em participar do trabalho.

Durante alguns momentos a aluna ficou inquieta com a possibilidade de estar atrapalhando, de estar sendo inadequada naquela situação e estar invadindo a privacidade da família. Mas tranqüilizou-se quando a mãe reconheceu o seu apoio dizendo: "é claro que não existe nada que você possa me falar que vai me tirar esta dor que eu sinto, mas o seu apoio é muito bom".

A seguir, a mãe quis saber o que o filho tinha falado e a aluna entregou o gravador para os pais ouvirem a sua interação com Y. Observou os pais enquanto ouviam a gravação e preocupou-se com a possibilidade de não gostarem do modo como agiu com Y.. Talvez tivesse exigido demais da criança. Porém, como em alguns momentos eles riram com a gravação, tranqüilizou-se. Percebeu neles um sentimento de confiança.

A mãe, após ouvir a gravação quis saber o que a aluna tinha achado da conversa com o seu filho. A aluna respondeu que $\mathrm{Y}$. informou que não teria se assustado ao ver $\mathrm{V}$. com duas punções venosas e no respirador entubado, pois havia sido preparado pela mãe antes de entrar na UTI.

A aluna pediu que a mãe falasse um pouco sobre os seus sentimentos. Neste momento, o pai demonstrou dificuldade em aceitar a situação, ao dizer que daria tudo para ter o filho de volta. A mãe, durante o relato, também demonstrou a sua revolta quando contou que "socava a parede e falava que não era justo". Ela sabia que a situação era grave e que estava perdendo o seu filho. A aluna percebeu que a mãe estava emocionada e perguntou se gostaria de parar de falar, mas a mãe achou bom "desabafar". A mãe dizia não acreditar no que estava acontecendo, mas que inconscientemente alguma coisa lhe falava que tinha que ser forte para superar a situação e aí vinha a raiva acompanhada de muito choro e murros pela parede. A dificuldade dos pais em aceitar a morte do filho coincide com as análises apresentadas por VALLE (1995), dentre outros.

Segundo a mãe, pela manhã a médica havia dado a notícia de que V. estava muito mal e que não tinha muita coisa que fazer por ele. Neste instante, a mãe refere que teve uma dor muito forte no peito, percebeu que seu filho estava indo embora, e o sentimento de perda a dominou. A mãe perguntou para a médica se foram desligados os aparelhos. Pediu que enquanto tivesse um "restinho, um pinguinho de vida que não desligassem o aparelho". Contou que chorou muito e que resolveu nesta hora explicar para o Y., que eles estavam perdendo o V., que ele já ia embora e que ia morar com o papai do céu. Depois, chorou muito enquanto o menino relutava em aceitar o fato, mas parou para analisar: "o médico não me deu três dias? Não me deu setenta e duas horas para ver se ele reage? Porque eu tenho que brigar agora comigo? Agora ele vai começar a dar algum sinalzinho, pelo menos algum sinalzinho. Tenho aquela esperança, sabe".

A aluna percebeu que a mãe relutava em aceitar a realidade e sentiu a necessidade de clarificar**** o que a mãe havia dito. Achou que ela estava se perdendo no tempo e estimulou-a a descrever o acontecimento desde a hora do acidente. Assim a mãe percebeu que as setenta e duas horas já haviam se esgotado e isto ajudou a mãe a perceber a realidade.

Ao finalizar esta interação, a aluna pediu que a funcionária da UTI colocasse o gravador perto do ouvido do V. e que soltasse a mensagem do Y.. Pediu para a mãe dizer a Y., caso ele perguntasse, que o trato tinha sido cumprido. Despediu-se dos pais e disse que voltaria no outro dia cedo.

Após sair da pediatria, a aluna começou a pensar em tudo o que tinha acontecido nesta tarde. Ficou preocupada com o estado em que V. se encontrava. Lembrou-se que, em algum momento, sua professora havia dito que já havia presenciado dois casos que foram diagnosticados como morte cerebral. As crianças fizeram três EEG, mas estes se apresentavam sempre isoelétricos. Constatou-se então, morte cerebral, mas as duas crianças sobreviveram sem seqüelas. A professora explicou que os estímulos das crianças poderiam estar muito fracos e, por isto, o aparelho não os captou. Diante disto, a aluna passou a ter esperanças, V. poderia ser a terceira criança a sobreviver sem seqüelas. Posteriormente, a aluna percebeu que desenvolveu mecanismos de defesa frente às suas dificuldades em lidar com a situação.

\section{ANÁLISE}

A identificação da aluna e a explicação sobre o trabalho desenvolvido aconteceu nesta interação. Nesta fase, a aluna reconhece que agiu de modo não terapêutico quando entregou o gravador para os pais ouvirem a interação com Y.. Sabia ser necessário a permissão da criança para tal ação e também, questionou-se diante do pedido da mãe em querer saber o que o filho tinha dito na entrevista. Discutindo com a orientadora, estas questões éticas foram analisadas no enfoque dos direitos

**** Clarificar: termo específico do referencial de Comunicação Terapêutica (STEFANELLI, 1993), significando esclarecer os significados da mensagem 
da criança e nos direitos legais dos pais sobre a criança, os quais acabam prevalecendo. ZAVASCHI (1993) menciona situações semelhantes, classificando-as como um dilema ético, ao descrever o conflito de informar o diagnóstico de terminalidade para a criança que deseja saber, quando os pais não autorizam.

A aluna ficou ansiosa quando a mãe quis saber detalhes sobre o trabalho. Foi necessário que ela descrevesse o seu papel neste processo. Neste momento, a aluna sentiu insegurança e receou não ser aceita, mas à medida que foi explicando percebeu a aceitação e a aprovação dos pais. Percebeu também que o apoio que estava oferecendo correspondia a uma necessidade expressa por eles. Segundo DOWNEY et al. (1995), as enfermeiras que atuam nas áreas críticas deveriam continuamente estar desenvolvendo a habilidade de oferecer apoio às famílias nesta situação. Acima de tudo, apoio contínuo é indispensável.

Nesta interação, a aluna demonstrou disponibilidade, aceitação e interesse, e percebeu que o papel mais importante que desempenhou nesta fase foi o oferecimento de apoio. O interesse, o envolvimento, a empatia, caracterizados no contato pessoal e informal da aluna com a criança e os pais, criaram condições para uma relação de confiança bem sucedida. Estas considerações assemelham-se às conclusões de JEFIDOFF \& GASNER (1993) em trabalho semelhante.

Quando a mãe se emocionou, a aluna sabia que era preciso compreender as necessidades e as reações emotivas dos membros da família ao interagir com eles (KYES \& HOFLING, 1985). Por isso, perguntou à mãe se gostaria de continuar a falar.

A aluna em nenhum momento tentou eliminar a esperança dos pais. De acordo com JEFIDOFF \& GASNER (1993), é preciso manter a esperança, mas é necessário que os pais sejam informados do estado da criança e que sejam mantidos dentro da realidade. Segundo ZAVASCHI (1993), no momento em que um filho adoece, por mais estruturada que seja a família, todos adoecem. Além do impacto que sofrem, sentem-se impotentes, incapazes por causa da doença e diante do desespero, muitas vezes lançam mão de mecanismos de defesa.

A morte enseja uma sensação de derrota, difícil de suportar, pois aprende-se no hospital sempre a lutar pela vida e pelo sucesso das intervenções. A aluna precisava se posicionar de forma apropriada, sem mecanismos de defesa, adequando-se às necessidades da situação real. Em alguns momentos deixou-se levar pela expectativa da mãe. Porém, percebeu que estava se envolvendo excessivamente.

Mediante a validação e a clarificação (STEFANELLI, 1993), a aluna estimulou a mãe a reconstituir os fatos ocorridos, compreendendo o que acontecia.

\section{INTERAÇÃO}

12/07/95. Quarta-feira. Local: Quarto ao lado da UTI Pediátrica

Horário: 9:30 horas

A aluna procurou a docente e foram para UTI. A aluna estava ansiosa, pensava na possibilidade de não encontrar V. na enfermaria, pensava na morte. Tranqüilizou-se, quando chegaram no quarto onde Y. esteve internado e encontraram a mãe sentada, as mãos enroladas em uma toalha, chorando.

A mãe contou que o filho estava do mesmo jeito e quando a docente falou que íamos entrar na UTI, a mãe sorriu e a aluna percebeu que a mãe esperava que elas detectassem alguma reação em V..

O quadro da criança não havia se alterado, ela continuava sem apresentar reações. Quando saíram da UTI, a aluna percebeu que a expectativa da mãe era grande e que não podia dar falsas esperanças. Imediatamente após vê-las, a mãe perguntou o que elas tinham achado do estado de V., mas ambas não tinham outra resposta, a não ser que ele estava do mesmo jeito.

A seguir, a aluna perguntou-lhe se desejava apoio espiritual de uma pessoa da sua religião, mas a mãe agradeceu dizendo que já estava recebendo ajuda .

$\mathrm{Na}$ despedida, a aluna disse que voltariam à tarde e colocou-se à disposição se precisasse de algo.

\section{ANÁLISE}

A aluna sentiu-se ansiosa, na expectativa do óbito da criança. Segundo DOWNEY et al. (1995), a enfermeira que trabalha com pacientes terminais é colocada frente ao luto pessoal devido à perda. A perda que a enfermeira sente, apesar de não ser tão intensa como a dos familiares, provoca também angústia e tristeza.

A aluna não deu falsas esperanças e, diante do sofrimento e da expectativa da mãe, ofereceu apoio espiritual. Segundo GROOT-BOLLÜJT \& MOURIK (1993), algumas pessoas têm necessidades especiais relativas à sua religião ou culto.

\section{INTERAÇÃO (Fase final)}

\section{2/07/95. Local: UTI Pediátrica}

Horário: 13:30 horas

A aluna entrou na enfermaria e percebeu um movimento anormal na porta da UTI. Muitas pessoas choravam, mas ela não reconheceu nenhuma. Procurou a mãe e o pai do V.. Não os encontrou. Ficou ansiosa. Avistou o pai entrando na enfermaria, esperou que ele se aproximasse.

O pai tocou no ombro da aluna e disse: "é isso ai M." e seguiu para abraçar as pessoas que choravam na porta da UTI. V. tinha falecido. 
A aluna ficou parada por alguns instantes e sentiu raiva, pela perda da criança. Inesperadamente sentiu que o relacionamento chegara ao fim.

Entrou na UTI e frente à dor, ao sofrimento e desespero da mãe em perder o filho, ficou em silêncio, procurou ouvi-la. Apoiou a família na expressão da sua dor: aproximou-se da mãe e tocou seus ombros, a mãe chorando, segurou a mão da aluna e disse: "perdi M., ele foi embora, ele me deixou". Em um determinado momento, a mãe se exaltou e foi necessário que a docente estabelecesse limites, solicitando-lhe que se contivesse para não assustar as demais crianças da UTI. A mãe estava chocada, recusava-se a aceitar o fato, mas conteve-se diante da colocação do limite. A mãe teve oportunidade de pegar o seu filho no colo, para o último contato físico. Depois de alguns minutos, uma funcionária da UTI chegou para os pais e disse que precisava levar V. para a patologia para necropsia. Os pais ficaram revoltados e através de vários telefonemas à autoridades com as quais se relacionavam, conseguiram momentaneamente que a intervenção fosse suspensa. A aluna procurou apoiá-los, levou-os até a patologia e permaneceu ao lado da família esperando a preparação do corpo. A mãe resolveu aguardar a liberação do corpo no carro, enquanto o pai tratava com a funerária local a conduta necessária para seguirem viagem. Houve momentos em que a mãe chorava muito e outros, em que ela esmurrava o carro e perguntava: "por quê? Por quê meu filho? Eu não vou mais vê-lo correndo e bagunçando a casa. Um pedaço de mim foi arrancado". A aluna permaneceu em silêncio e permitiu que a mãe expressasse a sua emoção.

O corpo foi liberado às 15:00 horas e a aluna acompanhou-os até a saída. Os pais a abraçaram e agradeceram o seu apoio. O pai dirigia-se para o carro quando, de repente parou, virou-se, olhou para a aluna, colocou a mão no bolso e pegou a carteira. Parou por um instante, olhou para a aluna, depois para a carteira, e imediatamente a colocou de volta no bolso. Estendeu a mão para a aluna em outra despedida. A aluna ficou chocada com a atitude do pai, que voltou atrás ao perceber a sua reação. Mais tarde, a aluna ficou sabendo que a necropsia foi inevitável por se tratar de um acidente, mas como isto aconteceu fora do hospital, ela não pode acompanhá-los.

\section{ANÁLISE}

Nesta interação, a aluna permaneceu em silêncio e ouviu os familiares diante da perda. Ficou triste com morte da criança e com raiva pela própria impotência diante do inevitável. Não sabia o que dizer-lhes para confortá-los.

Para KYES \& HOFLING (1985), as enfermeiras devem deixar que os familiares falem ou chorem, se é isso que eles precisam fazer. Tolerar seu comportamento, qualquer que seja ele, ajuda a família a começar o processo de luto, tão necessário a essa altura. Não ajuda nada darlhes a impressão de que não devem demonstrar emoção, que tudo deve ser concluído rapidamente, fazendo, por exemplo, com que o corpo seja removido rapidamente.

A aluna concorda com Boss apud SADALA (1995) que ver a morte como parte intrínseca do existir torna-se possível através da aproximação e da convivência com o morrer do homem, de um modo cuidadoso, desistindo radicalmente de todo derivar, concluir, explicar ou formar hipóteses. Esse tornar-se consciente da mortalidade confere aos nossos relacionamentos pessoais e profissionais a verdadeira dignidade, o verdadeiro significado que realmente lhes compete. Ao prestar assistência a esta família, o que a aluna pode fazer foi aproximar-se com a intenção de ajudá-los; procurou conhecê-los, compreendê-los, estimular a expressão da sua dor e executou os procedimentos necessários para o seu cuidado e o seu conforto. E não tendo nada para falar, expressou não verbalmente a solidariedade e a tristeza pela sua perda.

As medidas terapêuticas foram utilizadas pela aluna e o oferecimento de apoio foi eficaz até o último instante do relacionamento. Os agradecimentos dos pais tiveram um significado importante e corresponderam à confirmação do seu trabalho. A aluna interpretou o último gesto do pai como uma tentativa para expressar o seu agradecimento, mas sentiu-se aliviada por ele ter desistido do seu gesto, voltando a estender-lhe a mão como despedida.

\section{CONSIDERAÇÕES FINAIS}

Avaliando o trabalho desenvolvido, a aluna considera que teve muita dificuldade em enfrentar a situação de presenciar a morte da criança e o sofrimento da família. Em muitos momentos, como foi descrito no decorrer do trabalho, sentiu-se insegura, conflituosa, sem saber o que fazer, não só por nunca ter vivenciado situação similar, mas porque o que se colocava para ela não eram somente questões sobre comunicação e procedimentos de enfermagem, mas sobretudo questões éticas e sentimentos humanos em situação extrema.

Nesta situação, o seu conhecimento teórico de comunicação, estratégias para estimular a expressão, mas sobretudo o oferecimento de apoio e estabelecimento de limites foram percebidos como recursos de extrema utilidade. Obteve resultados positivos utilizando-os.

Por outro lado, a supervisão das docentes foi fundamental. Estas foram solicitadas muitas vezes, o que levou a aluna a compreender como o apoio que o 
profissional recebe nestas situações é efetivo para diminuir a ansiedade e propiciar boas condições de trabalho.

A aluna considera ainda que, embora muitas vezes tenha sido não terapêutica e não tendo desenvolvido o relacionamento terapêutico como preconizado teoricamente por SUNDEEN (1985), ela desenvolveu um importante relacionamento de ajuda aos familiares de V., com um objetivo definido, com a participação dos pais, alcançando o que se propunha: ofereceu-lhes apoio na situação traumática. $\mathrm{O}$ relacionamento de ajuda nesta situação exige um preparo especial, pois o prognóstico de terminalidade nos leva a refletir e a vivenciar os sentimentos mais extremos, porque freqüentemente $o$ envolvimento emocional ultrapassa o desejável. Concordamos com PERUZO et al. (1987) que afirmam a necessidade do trabalho de uma equipe multiprofissional que se proponha a discutir, de forma integrada, os casos clínicos e as próprias ansiedades mobilizadas pelos pacientes terminais, objetivando um melhor preparo frente à morte.

\section{SELF PERCEPTION OF A NURSING STUDENT IN DEVELOPING A HELPING RELATIONSHIP WITH THE RELATIVES OF TERMINAL STAGE CHILDREN}

The present study aims at reporting and analysing the therapeutic approach of children under intensive care and studying the relationship between nurse and mother. Facing the illness of a dying child and within a sometimes hostile and emotional environment, the student is trained to help the family and their problems. The student's own anxiety and difficulties in managing these situations are evaluated.

KEY WORDS: pediatric intensive care units, terminal patient, therapeutic relationship

\section{AUTO PERCEPCIÓN DE ALUMNA DE ENFERMERÍA AL DESARROLAR RELACIÓN DE AYUDA A FAMILIARES DE NIÑO EN FASE TERMINAL}

El presente studio tiene como finalidad relatar y analizar el proceso de relacionamiento terapéutico entre alumna de enfermería y la madre del niño internado en la unidad de cuidados intensivos pediátricos, en fase terminal. Utilizando técnicas de comunicación terapéutica y medidas terapéuticas de enfermería, la alumna desarrolla empatía con la madre del niño y sus familiares, proponiéndose ayudarlos a superar sus dificultades frente la fase terminal del niño. En el estudio, la alumna analiza su própia ansiedad y las dificultades que pasó debido a sus própios conflictos frente a la condición de su paciente terminal.

TÉRMINOS CLAVES: unidad de cuidados intensivos pediátricos, paciente terminal, relacionamiento terapéutico

\section{REFERÊNCIAS BIBLIOGRÁFICAS}

01. BOEMER, M.R. Sobre a morte e o morrer. São Paulo: Cortez, 1984.

02. BOEMER, M.R.; VALLE, E.R.M. O significado de cuidar de criança com câncer. Rev. Bras. Enfermagem, v. 41, n.1, p. 56-63, 1988.

03. COX, S.A. Pediatric trauma: special patients/ special needs. Rev. Crit. Care Nurs., v.17, n.2, p.51-61,1994.

04. DOWNEY, V. et al. Dying babies and associated stress in NICU nurses. Neonatal Netw., v. 14, n.1, p. 41-46, 1995.

05.GROOT-BOLLÜJT, W.; MOURIK, M. Bereavement: role of the nurse in the care of terminally ill and dying children in the pediatric intensive are unit. Rev. Crit. Care Med., v. 21, n. 9, p.391- 392, 1993.

06. HORTA, V.M.A. A criança e o perigo da morte. J. Pediatr., v. 52, p. 357-360, 1982.
07. JEFIDOFF, A, ; GASNER, R. Helping the parents of he dying child: an israeli experience. Pediatr. Nurs., v. 8, n. 6, p. 413-415, 1993.

08. KÜBLER-ROSS, E. Sobre a morte e o morrer. São Paulo: Martins Fontes, 1987.

09. KYES, J.J.; HOFLING, C.K. Conceitos básicos em enfermagem psiquiátrica. Rio de Janeiro: Interamericana, 1985. cap.8, p.127-136.

10. PERUZZO, A.; GUELFI, A.L.K.; CONCHIN, C.F.M.; BARROS, E.A.; CERVO, L.M.; LANNES, V.L.L. Considerações sobre a percepção da doença e da morte na criança, a propósito de um caso clínico. Momento \& Perspectiva Saúde, v. 1, n.1, p. 83, 1987.

11. SADALA, M.L.A. Estar com o paciente: a possibilidade de uma maneira autêntica de cuidar. São Paulo, 1995. p. 248 Tese (Doutorado) - Escola de Enfermagem, Universidade de São Paulo. 
12. Stefanelli, M.C. Comunicação com paciente: teoria e ensino. São Paulo: Robe, 1993.

13. STEFANELLI, M.C. et al. Aceitação, empatia envolvimento emocional no relacionamento enfermeira - paciente. Rev. Esc. Enfermagem USP., v. 16, n. 3, p. 245-53,1982.

14. SUNDEEN, S.J. et al. Nursing - client interaction: implementing the nursing process. Saint Louis: C.V. Mosby, 1985.
15. VALLE, E.R.M. Câncer infantil e psicologia

fenomenológica: compreender e agir. Ribeirão Preto, 1995. p.203. Tese (Livre Docência) Escola de Enfermagem de Ribeirão Preto, Universidade de São Paulo.

16. ZAVASCHI, M.L.S. A reação da criança e do adolescente à doença e à morte. Rev. Bioética, v. 1, n. 2, p.165-172, 1993. 